\title{
Haemodynamic changes caused by alteration of autonomic activity in patients with heart failure
}

Karl Josef Osterziel, Rainer Dietz, Joachim Manthey, Werner Schmid, Wolfgang Kübler

\begin{abstract}
In 14 patients with heart failure (New York Heart Association class 2-3) and sinus rhythm the carotid sinus baroreceptors were stimulated to induce a reflex mediated decrease of sympathetic efferent activity and a simultaneous increase in vagal tone. Five patients were in severe heart failure (New York Heart Association class 3) with raised plasma concentrations of noradrenaline at rest $(2.99(0.86) \mathrm{nmol} / 1$ (mean (SD)) and nine patients had less severe heart failure (class 2.2 (0.2)) and normal plasma concentrations of noradrenaline at rest. The haemodynamic responses during arterial baroreceptor stimulation were different in both groups. In all five patients with severe heart failure cardiac output increased whereas in the nine patients with less severe heart failure it was unchanged or decreased. The increase of cardiac output in the group with severe heart failure was solely the result of a significant increase of stroke volume index (by 9 (2) $\mathrm{ml} / \mathrm{m}^{2}$ ). In the nine patients with less severe heart failure stroke volume remained unchanged but heart rate decreased significantly by 7 (2) beats/min during baroreceptor stimulation.
\end{abstract}

These data show that an integrated change of autonomic activity consisting of a decrease in sympathetic tone and an increase in vagal activity leads to an increase of stroke volume in patients with severe heart failure and hence to haemodynamic improvement.

In patients with heart failure sympathetic tone is increased and parasympathetic activity is attenuated. ${ }^{1-3}$ As a consequence of the increased activity of vasopressor systems the total peripheral vascular resistance is raised and may contribute to a progressive deterioration of myocardial pump function. ${ }^{4-7}$ The adaptive changes of the autonomic nervous system in heart failure have been regarded as compensatory-that is, beneficial mechanisms to maintain adequate central blood pressure. ${ }^{8}$ However, sympathetic stimulation and vagal withdrawal not only induce inotropic and chronotropic effects but also increase impedance for the already impaired pump function of the left ventricle. Consequently, in certain circumstances the changes of autonomic tone might improve cardiac perfor- mance, but under other conditions the resulting haemodynamic effect may be deleterious.

We investigated the effects of instantaneous alterations in sympathetic and parasympathetic tone on cardiac performance in patients with either mild ( $\mathrm{New}_{\mathrm{c}}$ York Heart Association class 2) or more advanced stages of heart failure (New York Heart Association class 3).

\section{Patients and methods \\ PATIENTS}

We studied thirteen men and one woman (mean (SD) age 54 (3) years and range from 25 to 73 years) with heart failure and sinus rhythm. Five patients had coronary artery disease and nine had primary dilated cardiomyopathy. The diagnosis was confirmed in all patients by right and left heart catheterisation and by selective coronary angiography. All patients were treated with diuretics and 10 were being treated with digitalis; one patient was also given quinidine and another theophylline. All patients gave informed consent to the protocol, which was approved by the ethics committee of the German National Research Foundation, Herzfunktion und Ihre Regulation, SFB 320.

\section{HAEMODYNAMIC MEASUREMENTS}

We performed right heart catheterisation using a Swan-Ganz catheter in patients in the postabsorptive state. Cardiac output was measured by thermodilution at baseline in triplicate and once during each period of baroreceptor stimulation. Pulmonary artery and right atrial pressures were recorded. Arterial cannulas were inserted into the radial artery of six patients. The mean of three measurements by the cuff technique was taken as arterial pressure in the remaining patients. The following variables were calculated by standard formula: cardiac index, stroke volume index, mean blood pressure, total peripheral resistance.

Plasma concentrations of catecholamines were measured by the radioenzymatic method of $\mathrm{Da}$ Prada and Zürcher. ${ }^{9}$ Plasma renin activity and plasma vasopressin were measured by radioimmunoassays. ${ }^{11}$

EVALUATION OF THE CAROTID SINUS BAROREFLEX Carotid sinus baroreflexes were studied by means of the negative pressure technique described by Eckberg et al..$^{12}$ An airtight chamber was fastened around the neck and painless negative pressure was generated within $0 \cdot 1$ seconds. Steady state conditions were reached 
within 30 seconds. ${ }^{13-16}$ The negative pressure is linearly transmitted to the carotid sinus and selectively stimulates the carotid sinus baroreceptors, causing an immediate decrease of heart rate, and a delayed fall of arterial pressure. ${ }^{12-16}$

\section{STUDY DESIGN}

All patients were studied in the supine position. After 30 minutes of rest the baseline haemodynamic data were obtained and blood was drawn for the measurement of plasma concentrations of catecholamines and vasopressin and plasma renin activity. Then a negative pressure of $40 \mathrm{~mm} \mathrm{Hg}$ was applied to the neck chamber. During the last 20 seconds of negative pressure-that is, between the 30 th and 60th second of suction-the haemodynamic data were obtained. Negative pressure was applied twice to the neck of each patient and the mean of the haemodynamic data obtained during the two intervention periods was used for calculations.

The patients were divided into two groups according to a combination of their New York Heart Association class and plasma noradrenaline concentrations at rest. Patients with severe heart failure (New York Heart Association class 3) and simultaneously increased plasma noradrenaline concentrations at rest $(>1.48 \mathrm{nmol} / \mathrm{l})$ were allocated to group $\mathrm{A}$ whereas patients with mild heart failure (New York Heart Association class 2) or patients in New York Heart Association class 3 and normal concentrations of plasma noradrenaline at rest $(<1.48 \mathrm{nmol} / \mathrm{l})$ were allocated to group B. Plasma catecholamine concentrations that were more than $2 \mathrm{SD}$ above the mean of a group with normal left ventricular function $^{7}$ were regarded as raised. Both groups were similar in age. Four patients in group A and five patients in group B had dilated cardiomyopathy. The other patients had ischaemic cardiomyopathy.

Table 1 Comparison of haemodynamic data at baseline in patients with severe (group A) and moderate (group $B$ ) heart failure

\begin{tabular}{|c|c|c|c|}
\hline & Group $A$ & Group B & $p$ \\
\hline $\begin{array}{l}\text { Mean blood pressure }(\mathrm{mm} \mathrm{Hg}) \\
\text { Heart rate (beats } / \mathrm{min}) \\
\text { Cardiac index }\left(\mathrm{l} / \mathrm{min} \text { per } \mathrm{m}^{2}\right) \\
\text { Stroke volume index }\left(\mathrm{ml} / \mathrm{m}^{2}\right) \\
\text { Systolic pulmonary artery pressure }(\mathrm{mm} \mathrm{Hg}) \\
\text { Diastolic pulmonary artery pressure }(\mathrm{mm} \mathrm{Hg}) \\
\text { Mean right atrial pressure }(\mathrm{mm} \mathrm{Hg}) \\
\left.\text { Total peripheral vascular resistance (dyn } \mathrm{s} \mathrm{cm}^{5}\right)\end{array}$ & $\begin{aligned} 87 & (4) \\
98 & (11) \\
2 \cdot 4 & (0 \cdot 2) \\
26 & (2) \\
63 & (3) \\
30 & (4) \\
11 & (2) \\
1362 & (134)\end{aligned}$ & $\begin{aligned} 95 & (5) \\
82 & (4) \\
3 \cdot 2 & (0 \cdot 3) \\
39 & (3) \\
34 & (4) \\
16 & (3) \\
6 & (1) \\
1236 & (108)\end{aligned}$ & $\begin{array}{l}\text { NS } \\
\text { NS } \\
\text { NS } \\
0.02 \\
0.001 \\
0.01 \\
0.08 \\
\text { NS }\end{array}$ \\
\hline
\end{tabular}

Table 2 Changes of haemodynamic variables during baroreceptor stimulation in patients with severe (group $A$ ) and moderate (group $B$ ) heart failure

\begin{tabular}{|c|c|c|c|}
\hline & Group $A$ & Group B & p (between groups) \\
\hline $\begin{array}{l}\text { Heart rate (beats } / \mathrm{min}) \\
\text { Cardiac index }\left(1 / \mathrm{min} \text { per } \mathrm{m}^{2}\right) \\
\text { Stroke volume index }\left(\mathrm{ml}^{2} / \mathrm{m}^{2}\right)\end{array}$ & $\begin{array}{l}-3(3) \\
0 \cdot 8(0 \cdot 2)^{\star \star} \\
9(2)^{\star \star}\end{array}$ & $\begin{array}{l}-7(2)^{\star \star} \\
-0 \cdot 3(0 \cdot 1)^{\star} \\
0 \quad(1)\end{array}$ & $\begin{array}{l}\text { NS } \\
0.001 \\
0.01\end{array}$ \\
\hline $\begin{array}{l}\text { Systolic pulmonary artery pressure } \\
(\mathrm{mm} \mathrm{Hg})\end{array}$ & -10 & $-4 \quad(2)$ & NS \\
\hline $\begin{array}{l}\text { Diastolic pulmonary artery pressure } \\
\text { (mm Hg) } \\
\text { Mean right atrial pressure (mm } \mathrm{Hg} \text { ) }\end{array}$ & $\begin{array}{rr}-3 & (3) \\
0 & (1)\end{array}$ & $\begin{array}{rr}-1 & (2) \\
2 & (1)\end{array}$ & $\begin{array}{l}\text { NS } \\
\text { NS }\end{array}$ \\
\hline
\end{tabular}

${ }^{\star} \mathrm{p}<0.005,{ }^{\star \star} \mathrm{p}<0.01$ for changes compared with baseline values.
STATISTICAL ANALYSIS

Results are given as mean (SEM). The significance of differences was calculated by the $t$ test or the signed rank test on paired data and the $t$ test or the Mann-Whitney $U$ test on unpaired data. A p value of $<0.05$ was regarded as significant.

\section{Results}

All patients in group A but only two patients in group B had severe heart failure (New York Heart Association class 3). The other patients were in the New York Heart Association class 2. The New York class of group B (2.2 (0.2)) was lower than that in group A. By definition the mean plasma concentration of noradrenaline was much higher in group $A$ than in group B (2.99 (0.86) nmol/1 $v$ 0.85 (0.24) $\mathrm{nmol} / \mathrm{l})$.

Table 1 shows the baseline haemodynamic data of both groups. In group A pulmonary artery pressures were significantly higher and stroke volume index was significantly lower than in group B. Mean arterial pressure and heart rate did not differ significantly in the two groups.

Plasma renin activity in group B (4.0 (1.2) $\mathrm{ng}$ angiotensin $\mathrm{I} / \mathrm{ml} \mathrm{h}$ ) was significantly lower than in group A (7.8 (1.0 $\mathrm{ng}$ angiotensin $\mathrm{I} / \mathrm{ml}$ h) $(p<0.05)$. Plasma concentrations of vasopressin (3.3 (0.9) pmol/1 in group $A$ versus $3.2(0.7) \mathrm{pmol} / 1$ in group $B$ ) and plasma adrenaline (398.43 (131.00) v 278.36 (98.24) $\mathrm{pmol} / \mathrm{l}$ in group B) were not significantly different in the two groups.

Table 2 shows the haemodynamic responses to baroreceptor stimulation. Pulmonary artery and right atrial pressures did not change significantly in either group. The tendency for heart rate to fall during baroreceptor stimulation was similar in the two groups. All patients in group A had an increase of cardiac output during baroreceptor stimulation $(+1.5$ $(0.3) 1 / \mathrm{min}, \mathrm{p}<0.05)$ whereas in the nine patients in group $B$ cardiac output decreased or remained unchanged $(-0.6(0.2) 1 / \mathrm{min}, \mathrm{p}$ $<0.01)$. The increase of cardiac output during baroreceptor stimulation in group $A$ was caused by an increase in stroke volume (fig 1 , table 2). In group B mean heart rate decreased slightly and because stroke volume did not change cardiac output fell (fig 2, table 2).

The radial artery pressure was measured in three patients in each group during stimulation of the carotid sinus baroreceptors. Mean arterial pressure fell in five patients and remained unchanged in one patient in group $B$ (92 (5) v 77 (4) $\mathrm{mm} \mathrm{Hg}$; $p<0.05$ ). The number of patients was too small for the changes of blood pressure in each group to achieve statistical significance (table 3 ). In the three patients with severe heart failure (group A) systemic vascular resistance fell significantly $(p<0.05)$ whereas the systemic vascular resistance was not altered by baroreceptor stimulation in patients in group B (table 3). 

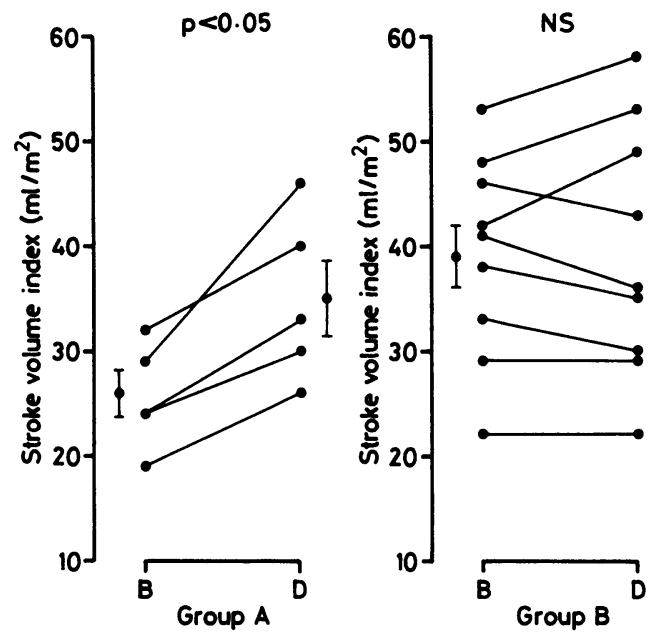

Figure 1 Stroke volume index before (B) and during (C) carotid sinus baroreceptor stimulation in patients with severe (group $A$ ) and less severe heart failure (group B).

\section{Discussion}

Congestive heart failure is associated with increased sympathetic drive to the heart and blood vessels. ${ }^{1217}$ In mild heart failure the increased sympathetic activity is considered to be compensatory to preserve cardiac output. In severe heart failure, however, excessive sympathetic tone can lead to a further deterioration of cardiac function. ${ }^{18}$ Physiological withdrawal of sympathetic tone could therefore unmask the effects of sympathetic overactivity. Stimulation of carotid sinus baroreceptors results in a physiological and almost instantaneous reflex withdrawal of sympathetic efferent activity and an increase of vagal efferent tone. ${ }^{32-16}$ This stimulus was therefore used to assess the haemodynamic changes caused by the alterations of autonomic tone.

The most interesting finding of this study was the instantaneous increase in cardiac output and stroke volume index in patients with severe heart failure (group A), indicating improved cardiac performance when the carotid sinus baroreceptors were stimulated by negative pressure.

The degree of carotid sinus baroreceptor stimulation must have been sufficient to alter the autonomic nervous efferent activity because the arterial pressure decreased significantly in the six patients in whom intraarterial pressure was monitored. In addition, in patients with mild to moderate heart failure the same degree of baroreceptor stimulation induced a $10 \mathrm{~mm} \mathrm{Hg}$ fall in blood pressure. ${ }^{19}$

Table 3 Intra-arterial pressure during baroreceptor stimulation in three patients in group $A$ and three patients in group $B$

\begin{tabular}{|c|c|c|c|c|}
\hline \multirow{5}{*}{$\begin{array}{l}\text { Mean blood pressure }(\mathrm{mm} \mathrm{Hg}) \\
\text { Heart rate (beats } / \mathrm{min}) \\
\text { Cardiac index }\left(\mathrm{l} / \mathrm{min} \text { per } \mathrm{m}^{2}\right) \\
\text { Stroke volume index }\left(\mathrm{ml} / \mathrm{m}^{2}\right) \\
\text { Mean right atrial pressure } \\
\text { (mm Hg) } \\
\text { Total peripheral vascular }\end{array}$} & \multicolumn{2}{|l|}{ Group A } & \multicolumn{2}{|l|}{ Group B } \\
\hline & Before & During & Before & During \\
\hline & $\begin{array}{ll}88 & (6) \\
95 & (4) \\
2 \cdot 7 & (0 \cdot 2) \\
28 & (2)\end{array}$ & $\begin{array}{l}72(6) \\
94(9) \\
3 \cdot 7(0 \cdot 3)^{\star} \\
40(4)^{\star}\end{array}$ & $\begin{array}{cl}97 & (8) \\
76 & (1) \\
3 \cdot 2 & (0 \cdot 2) \\
42 & (2)\end{array}$ & $\begin{array}{cc}84 & (1) \\
69 & (1)^{\star} \\
2 \cdot 6(0 \cdot 1) \\
38 \quad(3)^{\star}\end{array}$ \\
\hline & (3) & (4) & 7 (1) & (1) \\
\hline & 1245 & $729(71)^{\star}$ & 1141 (109) & $1233 \quad(55)$ \\
\hline
\end{tabular}

Significance of differences with the baseline values ${ }^{\star} p<0.005$.
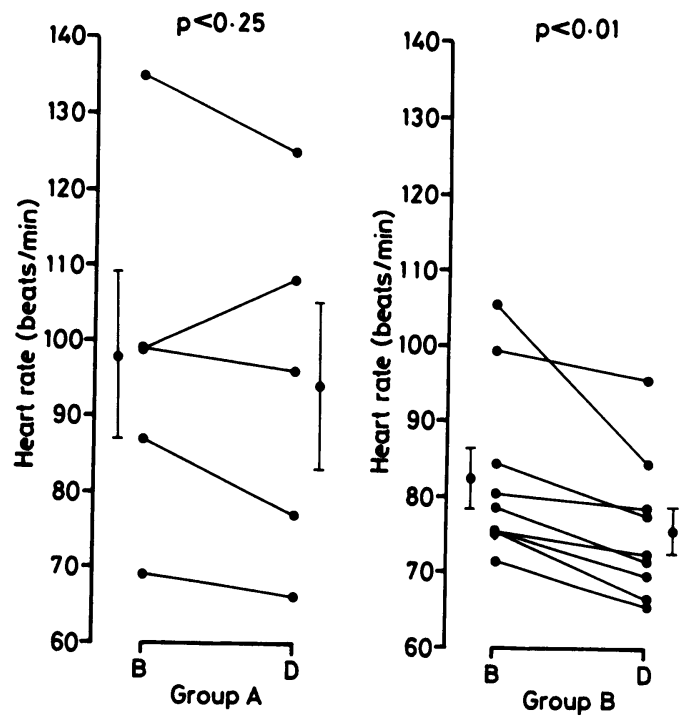

Figure 2 Heart rate before (B) and during (D) stimulation of the carotid sinus baroreceptors.

Moreover, in normal subjects the same stimulus led to reflex changes of cardiac output, blood pressure, and forearm vascular resistance..$^{20-25}$ The hypotensive response after electrical stimulation of the carotid sinus nerves in man is not affected by atropine and therefore must be the result of a reduction in sympathetic vasoconstrictor tone and/or cardiac sympathetic activity. ${ }^{26}$ The decrease of heart rate in all patients in group B and in four patients in group A was further indirect evidence that the autonomic tone was altered by the degree of negative pressure that we applied. The activities of the renin-angiotensin or vasopressin system or alterations of body fluid volumes do not change during such short periods of baroreceptor stimulation, and therefore could not have affected the haemodynamic response. Because all cardiovascular reflex changes mediated by arterial baroreceptors are achieved by an integrated response of the autonomic nervous system we concluded that sympathetic tone was reduced and that vagal tone was simultaneously increased during this degree of baroreceptor stimulation. ${ }^{16}$

All patients in group $\mathbf{A}$ had heart failure in the New York Heart Association class 3, high concentrations of plasma noradrenaline, and high renin activity. Left ventricular filling pressure was higher and stroke volume was lower than in group B. Heart rate tended to be higher in patients in group A. Therefore, patients in group A had more severe heart failure with a greater degree of sympathetic stimulation than patients in group $B$.

The changes in stroke volume during baroreceptor stimulation of the carotid sinus in group A could be the result of alterations of preload, afterload, and/or inotropic state. Diastolic pulmonary artery pressure (a measure of left ventricular filling pressure) was unchanged in group A during baroreceptor stimulation. The increase of stroke volume in group A could therefore not be explained by an altered preload. Consequently, the increase of stroke volume must have been produced by alterations in the inotropic state or afterload or both. 
The substantial decrease of total peripheral vascular resistance during baroreceptor stimulation suggests that the stroke volume was increased by a large decrease in left ventricular afterload. The decrease in afterload was caused by a reduction in the sympathetic vasoconstrictor tone, a reflex response that was reported in animals and humans. ${ }^{12-16}{ }^{19-26} \mathrm{~A}$ simultaneous increase in inotropic state seems less likely. The beneficial effect of a nearly immediate reduction in sympathetic tone on stroke volume provides evidence that sympathetic overactivity may be detrimental in human heart failure; reflex sympathetic withdrawal improved the patient's condition. This mechanism might also explain the poor prognosis in patients with high degrees of sympathetic activity. ${ }^{2}$

The reflex decrease of heart rate during stimulation of the carotid sinus baroreceptors in patients with heart failure was abolished by atropine and therefore must depend on an increase in vagal efferent tone. ${ }^{316}$ The same mechanism may be assumed in group A because heart rate decreased slightly in four out of five patients.

In contrast, the patients with only mild or moderate degrees of left ventricular dysfunction (group B) showed haemodynamic responses to stimulation of the carotid sinus baroreceptors that resembled those in healthy subjects. Direct stimulation of the carotid sinus nerve and stimulation of the carotid sinus baroreceptors by negative pressure caused a slight decrease in heart rate in healthy volunteers. ${ }^{20-25}$ Cardiac output was either unchanged ${ }^{23}$ or decreased ${ }^{2024}$ during $40 \mathrm{~mm} \mathrm{Hg}$ of negative pressure. The same degree of baroreceptor stimulation in group B caused a fall in cardiac output owing to a reduction in heart rate. The design of our study meant that we were unable to determine why stroke volume was unchanged. The unaltered systemic vascular resistance at a presumably lower blood pressure suggests that withdrawal of sympathetic vasoconstrictor tone caused a decrease in left ventricular afterload. Because preload did not change during baroreceptor stimulation the likely explanation was that a reflex withdrawal of the inotropic sympathetic support to the heart was balanced by a reduction of afterload, resulting in an unchanged stroke volume. The degree of autonomic activity in these patients may therefore be regarded as a compensatory response to preserve cardiac output.

The results of this study show that patients with severe heart failure may benefit from withdrawal of their intrinsic autonomic tone. Drugs that reduce the sympathetic tone may lead to haemodynamic improvement in such patients.

This research was supported by a grant from the Deutsche This research was supported by a grant from the Deutsche Forschungsgemeinschaft within the SFB
und ihre Regulation, University of Heidelberg.
1 Leimbach WN, Wallin BG, Victor RG, Aylward PE Sundlöf G, Mark AL. Direct evidence from intraneural
recordings for increased central sympathetic outflow in recordings for increased central sympathetic outflow

2 Cohn JN, Levine TB, Olivari MT, et al. Plasma norepinephrine as a guide to prognosis in patients with chronic congestive heart failure. $N$ Engl $J$ Med 1984;311: 819-23.

3 Eckberg DL, Drabinsky M, Braunwald E. Defective cardiac parasympathetic control in patients with heart disease. $N$ Engl J Med 1971;285:877-83.

4 Dzau VJ, Hollenberg NK, Williams GH. Neurohumoral mechanisms in heart failure: role in pathogenesis, therapy, and drug tolerance. Fed Proc 1983;42:3162-9.

5 Francis GS, Goldsmith SR, Levine TB, Olivari MT, Cohn JN. The neurohumoral axis in congestive heart failure. Ann Intern Med 1984;101:370-7.

6 Levine TB, Francis GS, Goldsmith SR, Simon AB, Coh JN. Activity of the sympathetic nervous system and renin-angiotensin system assessed by plasma hormone levels and their relation to hemodynamic abnormalities in congestive heart failure. Am J Cardiol 1982;49:1659-66.

7 Manthey J, Dietz R, Hackenthal E, et al. Linksventrikuläre Funktion und Aktivität vasopressorischer Systeme be Patienten mit chronischer Herzinsuffizienz. Z Kardiol 1984;73:279-88.

8 Zelis R, Mason DT. Compensatory mechanisms in congestive heart failure-the role of the peripheral resistance vessels. N Engl J Med 1970;282:962-4.

9 Da Prada M, Zürcher G. Simultaneous radioenzymatic determination of plasma and tissue adrenaline, noradrenaline and dopamine within the femtomole range. Life $S C i$ 1976;19:1161-74.

10 Haber E, Koerner T, Page LB, Kliman B, Purnode A. Application of a radioimmunoassay for angiotensin I to the physiologic measurements of plasma renin activity in the physiologic measurements of plasma renin activity in normal $1349-55$.

11 Robertson GL, Mahr EA, Athar S, Sinha T. Development and clinical application of a new method for the radioim munoassay of arginine vasopressin in human plasma. Clin Invest 1973;52:2340-52.

12 Eckberg DL, Cavanaugh MS, Mark AL, Abboud FM. A simplified neck suction device for activation of carotid baroreceptors. J Lab Clin Med 1975;85:167-73.

13 Ludbrook J, Mancia G, Ferrari A, Zanchetti A. The variable-pressure neck-chamber method for studying the carotid baroreflex in man. Clin Sci Mol Med 1977;53: 165-71.

14 Thron HL, Brechmann W, Wagner J, Keller K. Quantitative Untersuchungen über die Bedeutung der Gefässdehnungsreceptoren im Rahmen der Kreislaufhomoiostase beim wachen Menschen. Pflügers Arch 1967;293: 68-99.

15 Korner PI, West MJ, Shaw J, Uther JB. 'Steady-state' properties of the baroreceptor-heart rate reflex in essential properties of the baroreceptor-heart rate reflex in essential 1:65-76.

16 Mancia G, Mark AL. Arterial baroreflexes in humans. In: Shepherd JT, Abboud FM, eds. American Physiological Society: Handbook of physiology-the cardiovascular system III. Baltimore: Waverly Press, 1983:755-93.

17 Hasking GJ, Esler MD, Jennings GL, Burton T, Johns JA, Korner PI. Norepinephrine spillover to plasma in congestive heart failure: evidence of increased cardiorenal and total sympathetic activity. Circulation 1986;73:615-21.

18 Packer M, Wai Hung L, Kessler PD, Gottlieb SS, Bernstein $\mathrm{JL}$, Kukin ML. Role of neurohumoral mechanisms in determining survival in patients with severe chronic heart failure. Circulation 1987;75 (suppl IV):80-92.

19 Osterziel KJ, Röhrig N, Dietz R, Manthey J, Hecht J Kübler W. Influence of captopril on the arterial baroreceptor reflex in patients with heart failure. Eur beart $J$ 1988;9:1137-45.

20 Bevegard BS, Shepherd JT. Circulatory effects of stimulat ing the carotid stretch receptors in man at rest and during ing the carotid stretch receptors in man

21 Epstein SE, Beiser GD, Goldstein RE, et al. Treatment of angina pectoris by electrical stimulation of the carotidsinus nerve. N Engl J Med 1969;280:971-8.

22 Eckberg DL. Adaptation of the human carotid baroreceptorcardiac reflex. J Physiol 1977;269:579-89.

23 Bjurstedt H, Rosenhamer G, Tyden G. Cardiovascular responses to changes in carotid sinus transmural pressure in man. Acta Physiol Scand 1975;94:497-505.

24 Bevegard S, Castenfors J, Lindblad LE. Effect of carotid sinus stimulation on cardiac output and peripheral vascular resistance during changes in blood volume distribution in man. Acta Physiol Scand 1977;101:50-7.

25 Carlsten A, Folkow B, Grimby G, Hamberger CA, Thulesius $\mathrm{O}$. Cardiovascular effects of direct stimulation of the carotid sinus nerve in man. Acta Physiol Scand $1958 ; 44: 138-45$.

26 Borst C. Circulatory effects of electrical stimulation of the carotid sinus nerves in man. Amsterdam: University of Amsterdam, 1979. PhD thesis. 